\title{
Computer Classroom Construction Strategy of Art University Based on Flipped Classroom
}

\author{
Gang Chen, Dawei Zhao, Chunling Xu
}

College of Humanities \& Sciences of Northeast Normal University, Changchun, Jilin, 130117

Keywords: Computer Classroom Construction Strategy, Art University, Flipped Classroom

\begin{abstract}
The Basic Computer Courses in College is a foundation course for non-computer majors in colleges and universities, which has a wide range of benefits. However, the current method of computer-based traditional teaching faces many problems. With the development and prevalence of MOOC and other online teaching videos, flipped classroom has become a hot spot in teaching reform in the information age by virtue of its advantages. Under this background, this paper explores the use of MOOC flip classroom to solve teaching problems of basic computer teaching.
\end{abstract}

\section{Introduction}

The computer foundation of college students is a compulsory course for non-computer majors. University computer basic teaching is not only an important part of university general education, but also cultivates college students subtly to develop professional problems with computational thinking and become complex innovative talents Basic education. However, with the popularization of computers, all primary and secondary students have successively set up information technology courses. Due to their different regions, students from different regions have different backgrounds. Students in some regions have mastered certain computer knowledge. However, students in some remote mountain regions have never Contact the computer. Students with better fundamentals feel that university programs are too simple and have no interest in learning. No basis for classmates, I feel progress too fast to keep up, frustration. So it is always a problem that the basic course of computer science in the university is always speaking.

With the continuous development of computer technology, more and more teaching contents are carried on undergraduates' basic computer courses, and the curriculum capacity is also getting bigger and bigger. However, the total teaching hours cannot increase, to the course of teaching increased difficulty. It is also due to computer technology updates faster. University training students not only to impart knowledge, but more important is to develop students' lifelong learning ability. As students grasp the different levels of basic computer knowledge, so that teachers teaching progress and teaching content is to grasp. In this issue, many schools adopt hierarchical teaching. However, this teaching problem is that we cannot mobilize the basic weak students in order to catch up with the enthusiasm of good students, but also cannot be mobilized to start a good foundation students continue to study hard. The function of education is to awaken people's consciousness. Just as UNESCO said in "Learning to Survive," education in a school turns the object of education into self-education and turning others' education into one's own education. University computer basic teaching generally adopts the traditional teaching mode, the teacher first talk about the first demonstration, the student does again. Teachers are the main body of teaching, students are only passive learning, imitation, cannot take the initiative to learn. This teaching mode can only achieve the purpose of imparting knowledge and application skills to students and cannot meet the requirements of teaching steering committee of computer foundation course offered by the Ministry of Education to train students' cognition ability of computer, ability of using computer to solve problems, Collaborative ability and lifelong learning ability of this goal. Therefore, it is necessary to reform the teaching of computer-based, to cultivate students' thinking modes of computer science, to improve their ability to solve problems and to innovate their practical ability. 


\section{The Meaning and Advantages of the Flipped Classroom}

Today, turning the classroom can become a teaching mode of concern to the global education community, which is different from the traditional teaching mode in which teachers impart knowledge in the classroom and students' internal knowledge through exercises and assignments. Flipped Classroom is a way of turning over traditional teaching, asking students to internalize knowledge by watching video learning before class, and through classroom interaction with teachers, proper practice and group discussion. The flip-over class was invented by American chemistry teacher Jon Bergmann and Aaron Sams, who make up-for-students lessons and post videos that incorporate live tutorials and PPT presentations to the web for students to view Video to learn the knowledge that falls due to lack of class. [4] Turning the classroom up for grabs can be attributed to Salman Khan and his Khan Academy.

Students according to their own level, choose the teaching content and teaching progress. Basically weak students can be slower, see more times. Students who have spare capacity can also expand their study to achieve individualized teaching based on their aptitude. The teaching mode not only enables students to master the knowledge they have learned, but also helps to cultivate students 'autonomous learning ability and lays the foundation for students' lifelong learning. Can make teaching do not have to be limited to the specified time and place, that is, to make teaching breakthrough time and space constraints. Flip the classroom to break the traditional teaching-teacher-centered teaching structure after the first school, into a student-centered, first teaching structure. The course of knowledge internalization in class is the process of interaction between teachers and students, the process of cooperation between students, personal counseling and personalized education of students and teachers, and the cultivation of students' ability of cooperation.

Flip classroom was first widely used in the teaching of primary and secondary education in the United States, at present the country is also more and more primary and secondary education. In China, Jiangjin Juquhong Middle School in Chongqing and the Fifth High School in Haizhu District of Guangzhou City have implemented the "flip classroom" and obtained good teaching results. Higher education applications flip class is relatively less. Professor Franklin College of the United States combined with the practice of linear algebra curriculum summed up the "flip classroom" implementation model and achieved good teaching results.

\section{The MOOC Flipped Classroom Mode}

Flip classroom production is a product of MOOC resource sharing, and the micro-curriculum is different, it re-adjust the time inside and outside the classroom, by the students themselves to master the initiative of learning, teachers create teaching videos based on student situations, students watch teaching videos Learn the traditional classroom teaching content, back to classroom teachers and students face to face to communicate and complete the homework such a teaching form. "Turn the classroom" by many scholars attention, has the following several distinct advantages:

Adjust the time inside and outside the classroom, breaking the time and space constraints of the traditional classroom teaching mode. The traditional teaching model of classroom teaching time and space are mainly classroom teaching, if you want to develop to extra-curricular, there are many obstacles, which became the bottleneck of teaching reform and teaching quality improvement. The flip classroom teaching mode is to create short teaching videos by teachers, students can use extra-curricular time in any network where to learn teaching video, compared to the traditional classroom teaching mode, flip the classroom teaching mode will shift the classroom teaching time, Teachers and students can use valuable classroom teaching time to interact, practice and in-depth learning, students' learning time is not limited by time and space, and learning efficiency is better.

The short teaching videos help to control students' attention and improve their learning efficiency. Most flip classroom teaching video only a few minutes longer than the length of the video playback is generally only 10 minutes, and each video has a strong independence and pertinence, are targeted at a particular issue, you can stimulate students Think and communicate, and coincides with the fact 
that college basic computer courses are numerous and independent of each other. Compared with 45 minutes of traditional classroom teaching, flip the classroom is conducive to control the student's attention, can greatly reduce the visual fatigue of people, so as to stimulate students' interest in learning and improve learning efficiency.

\section{The Computer Flip Classroom Teaching Mode Based On MOOC}

Create teaching short video. The content of college basic computer courses is independent of each other, and MOOC's flip classroom teaching mode is short and lean, which is conducive to students' independent learning. According to the teaching objectives, teaching tasks, difficulties, teachers can focus on the module recording short videos and teaching the production of the corresponding test questions, pay more attention to the emotional development of students; can also be based on the actual situation of students choose the appropriate teaching video, serious study and self-dressing Knowledge system, and guide students to learn.

Develop students' ability to learn. The main reason that the traditional classroom teaching mode shows insufficient stamina in cultivating students' autonomous learning ability and independent learning ability is that teachers only teach basic knowledge in the classroom, while more difficult knowledge such as expanding knowledge and practice is left as a problem after class, Require students to find their own information, the lack of guidance of students, it is difficult to complete, but also difficult for teachers to accurately grasp the completion of student assignments. For the flip classroom teaching mode, teachers can use the MOOC big data platform to see each student to see information, do test questions and other specific circumstances, but also through this platform, teachers can also achieve the curriculum objectives to achieve a periodic review, give accurate feedback on learner learning, so as to accurately grasp the effectiveness of teaching process design, and promote teaching reform. Students can engage in heated discussion with other students in the community. According to the students 'problems, teachers can explain them in a targeted manner so as to better mobilize students' autonomy in learning.

Flip the most important feature of the classroom is to adjust the time inside and outside the class, the transfer of basic knowledge in the classroom from class to extracurricular, but the classroom valuable time can be used for teacher-student interaction, practice and in-depth knowledge of learning. Computer basic course in colleges and universities is a practical course, teachers can guide students to make full use of extra-curricular time to watch the teaching video to learn the basic content of the course, summed up before the study video to watch the learning situation, to students do not understand or problem Multiple questions set the discussion topic as a reference and upload it to the platform. In the classroom, students are allowed to use the contents of their study groups to conduct seminar-based learning and collaborative learning in a specific environment. Teachers then arrange the students to come to stage to explain. The groups can also evaluate each other and express different opinions to improve the quality of learning activities. Throughout the classroom, the role of teacher has changed from a content presenter to a learning coach, becoming a helper and mentor for student learning.

According to the students watch their own video teaching. Flip classroom teaching video short and pithy and can be repeated learning, students can choose according to their own computer whether to repeat the teaching video, or choose to repeat part of the teaching video is conducive to solving the problem of students starting point for large differences in teaching difficulties, it also has a great effect on the cultivation of students' abilities. Students can conduct autonomous learning even in the absence of a teacher. Pre-class study combined with course activities. For the flip classroom teaching mode, the students are based on a small video flip classroom teaching pre-class learning. Students follow the teacher's pre-designed teaching plan, learn the teaching video and complete the corresponding exercises, during which students can put forward their own questions to discuss with other students or to the teacher for help. Teachers summed up the problem group to carry out a variety of classroom activities, such as organizing group discussions, teacher-student interaction, taking the stage to explain and demonstrate practical products. This activity is of great help to the construction of students 'knowledge, and also can increase students' motivation to learn. 


\section{Conclusions}

Flip classroom is a new teaching model, has been recognized by many experts and teachers. Exploring MOOC-based computer-based flip classroom teaching mode has an important student value to improve the quality of computer-based teaching in colleges and universities. This paper through to explore and found that MOOC-based computer flip classroom teaching mode theory can improve teaching effectiveness, but its successful implementation is affected by many factors, on how to implement MOOC under the computer-based flip classroom teaching model needs further study and solve.

\section{Acknowledgements}

Project Name: Study on Improving Information Literacy of Art College Students

Contract No.: JJKH20170983SK

Project name: University computer flip class practice research

No.: ZHE101847

\section{References}

[1] Once star, Zhou Qingping, Cai Guomin. Study on MOOC-based Flip Classroom Teaching Model [J]. China Telephone Education, 2015, 4

[2] Zhang Jinlei, Wang Ying, Zhang Baohui. Flip classroom teaching model [J]. Distance Education Magazine, 2012, 4

[3] Bu Caoli, Ma Ying camp. Feasibility analysis of overturning classroom teaching mode in China's colleges and universities [J]. Software Guide, 2013, 7

[4] Wang Wenli. MOOC development and its impact on higher education [J]. Teaching Research, 2013, 2

[5] Chen Guoliang, Dong Rongsheng. Computational thinking and basic computer education in university [J]. China University Teaching, 2011 (0 1): 9 -13. 